\title{
Fungal root endophyte associations of plants endemic to the Pamir Alay Mountains of Central Asia
}

\author{
Szymon Zubek • Marcin Nobis • Janusz Błaszkowski • \\ Piotr Mleczko • Arkadiusz Nowak
}

Received: 12 September 2011 / Accepted: 28 October 2011 /Published online: 19 November 2011

(C) The Author(s) 2011. This article is published with open access at Springerlink.com

\begin{abstract}
The fungal root endophyte associations of 16 species from 12 families of plants endemic to the Pamir Alay Mountains of Central Asia are presented. The plants and soil samples were collected in Zeravshan and Hissar ranges within the central Pamir Alay mountain system. Colonization by arbuscular mycorrhizal fungi (AMF) was found in 15 plant species; in 8 species it was of the Arum type and in 4 of the Paris type, while 3 taxa revealed intermediate arbuscular mycorrhiza (AM) morphology. AMF colonization was found to be absent only in Matthiola integrifolia, the representative of the Brassicaceae family. The AM status and morphology are reported for the first time for all the species analyzed and for the genera
\end{abstract}

S. Zubek $(\bowtie) \cdot$ P. Mleczko

Laboratory of Mycology, Department of Plant Taxonomy,

Phytogeography and Herbarium, Institute of Botany,

Jagiellonian University,

Lubicz 46,

31-512 Kraków, Poland

e-mail: szymon.zubek@uj.edu.pl

\section{Nobis}

Department of Plant Taxonomy, Phytogeography and Herbarium, Institute of Botany, Jagiellonian University,

Kopernika 31,

31-501 Kraków, Poland

J. Błaszkowski

Department of Plant Protection,

West Pomeranian University of Technology,

Słowackiego 17,

71-434 Szczecin, Poland

\section{A. Nowak}

Laboratory of Geobotany and Plant Conservation,

Department of Biosystematics, Opole University,

Oleska 48,

45-022 Opole, Poland
Asyneuma, Clementsia, and Eremostachys. Mycelia of dark septate endophytes (DSE) accompanied the AMF colonization in ten plant species. The frequency of DSE occurrence in the roots was low in all the plants, with the exception of Spiraea baldschuanica. However, in the case of both low and higher occurrence, the percentage of DSE root colonization was low. Moreover, the sporangia of Olpidium spp. were sporadically found inside the root epidermal cells of three plant species. Seven AMF species (Glomeromycota) found in the trap cultures established with soils surrounding roots of the plants being studied were reported for the first time from this region of Asia. Our results provide information that might well be of use to the conservation and restoration programmes of these valuable plant species. The potential application of beneficial rootinhabiting fungi in active plant protection projects of rare, endemic and endangered plants is discussed.

Keywords Arbuscular mycorrhiza (AM) - Arbuscular mycorrhizal fungi (AMF) species diversity Arum/Paris morphotypes - Conservation - Dark septate endophytes (DSE) · Glomeromycota

\section{Introduction}

The Pamir Alay Mountains are a Central Asian mountain system situated on the border of subtropical and temperate climatic zones. Both this location and the system's considerable variations in altitude are favourable to a high floristic diversity. The Central Asian mountains have therefore been recognized by Conservation International as being among thirty-four of the world's biodiversity "hotspots" (Mittermeier et al. 2005) and as one of the eleven most important focal points for future plant diversity 
studies and conservation (Giam et al. 2010; Nowak et al. 2011). Especially interesting are the mountain ranges of central part of the Pamir Alay Mountains, situated almost exclusively in the area of Tajikistan. The flora of this region comprises ca. 4,500-5,000 vascular plant species of which approximately 1,486 species are generally accepted as endemics (endemics sensu stricto and sub-endemics) (Rasulova 1991; Nobis 2011; Nowak et al. 2011). Many of them are endangered as a result of anthropogenic activity and global climate change (Safarov 2003; Malcolm et al. 2006; Nowak et al. 2011). However, studies relating to their conservation are, as yet, insufficient (Myers et al. 2000; Lamoreux et al. 2006; Nowak and Nobis 2010; Nowak et al. 2011). Moreover, no investigations on the fungal root associations of these valuable species have been conducted to date, although there is a need for interdisciplinary studies on the biology and ecology of this group of plants to develop effective methods of their maintenance and propagation (Turnau and Haselwandter 2002; Zubek et al. 2008, 2009; Bothe et al. 2010). Arbuscular mycorrhizal fungi (AMF), as well as some strains of dark septate endophytes (DSE) have been found to stimulate the growth and vitality of plants (reviewed by Smith and Read 2008 and Newsham 2011). In view of the beneficial role of these microorganisms, both AMF and some strains of DSE are considered to be crucial for the maintenance and conservation of rare, endemic and endangered plants (Turnau and Haselwandter 2002; Fuchs and Haselwandter 2004; Zubek et al. 2009; Wu and Guo 2008; Bothe et al. 2010; Wu et al. 2010). The aim of our studies was therefore to determine the mycorrhizal status, the degree of root colonization by AMF and other fungal endophytes, and to evaluate the morphotypes of arbuscular mycorrhiza (AM) of selected endemic plants of the Pamir Alay Mountains. We also isolated and identified AMF species associated with the taxa being investigated. Such research is deemed a prerequisite for successful plant conservation efforts (Turnau and Haselwandter 2002; Bothe et al. 2010).

\section{Materials and methods}

\subsection{Study area and material sampling}

The material was collected in June 2010 from selected locations in the Pamir Alay mountain system of Tajikistan, in Central Asia. The characteristics of the sites are given in Table 1. More detailed information on the taxonomic structure, distribution and habitat preferences, as well as the conservation status of endemic and sub-endemic plant species of the Pamir Alay Mountains was presented by Nowak and Nobis (2010) and Nowak et al. (2011). On the whole, 16 taxa from 12 families were collected during the flowering and early seed formation period. The roots were carefully excavated with surrounding soil. The root systems, or their fragments, were then placed in plastic containers holding $50 \%$ ethanol in water. The soil samples were dried at room temperature and then transported in plastic bags to the laboratory. Site numbers, the plant species collected, the sample size and the sampling locations are presented in Table 1. The plant materials were deposited in the Herbarium of the Institute of Botany, at the Jagiellonian University in Kraków (KRA).

\subsection{Root staining and the assessment of fungal colonization}

Only the roots attached to the main roots of the plants were used for the evaluation of fungal colonization, in order to avoid the possibility of assessing roots from other species. The roots were prepared according to the modified Phillips and Hayman (1970) method. After being washed in running tap water, the roots were cleared in $10 \% \mathrm{KOH}$ for $24 \mathrm{~h}$ and subsequently rinsed in water. The material was acidified in $5 \%$ lactic acid in water for $24 \mathrm{~h}$, then stained with $0.05 \%$ aniline blue in $80 \%$ lactic acid for $72 \mathrm{~h}$ and finally stored in $80 \%$ lactic acid until analyzed. The entire procedure was carried out at room temperature. Root fragments approximately $1 \mathrm{~cm}$ long were mounted on slides in glycerol:lactic acid (4:1) and pressed, using coverslides. The number of root fragments analyzed per sample is presented in Table 1.

The presence of arbuscular mycorrhiza (AM) structures, namely arbuscules, vesicles and coils, the morphology of AM colonization, and the occurrence of other root endophytes, such as dark septate endophytes (DSE) and fungi from the genus Olpidium, were assessed by means of a Nikon Eclipse 80i light microscope with Nomarski interference contrast optics, using an objective of $40 \times$. The AM morphology was identified on the basis of AMF hyphae growing: (1) intercellularly, forming arbuscules terminally in cortical cells (Arum-type AM morphology), (2) intracellularly with arbuscules developed on coils (Paris-type) or (3) forming intermediate AM morphotypes (Dodd et al. 2000; Dickson 2004; Smith and Read 2008). The AM-type colonization by fine endophyte, usually considered as being Glomus tenue (Greenall) I.R. Hall (Thippayarugs et al. 1999; Dodd et al. 2000), was counted separately from the coarse AM-type colonization. The fine endophyte was identified on the basis of the following characteristics: mycelium ca $1 \mu \mathrm{m}$ in diameter, the hyphae usually stained deep blue, and the presence of small vesicles or swellings and fan-shaped branches (Dodd et al. 2000).

Mycorrhizal colonization analyses were conducted in line with the Trouvelot method (Trouvelot et al. 1986). The 


\begin{tabular}{|c|c|c|c|c|c|c|c|c|c|c|c|c|c|c|}
\hline 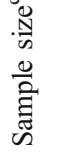 & 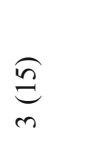 & $\underset{n}{\stackrel{\theta}{\ominus}}$ & $\underset{m}{\stackrel{\frac{n}{2}}{\rightleftarrows}}$ & $\underset{m}{\stackrel{\ominus}{g}}$ & $\underset{m}{\stackrel{\theta}{\sigma}}$ & $\begin{array}{l}\widehat{\delta} \\
\text { in }\end{array}$ & $\underset{n}{\stackrel{n}{n}}$ & 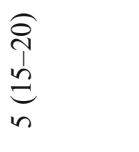 & $\begin{array}{l}\underset{\mathfrak{N}}{i} \\
\stackrel{n}{n}\end{array}$ & 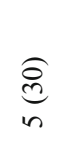 & $\underset{n}{\frac{\sigma}{2}}$ & $\underset{n}{\stackrel{\theta}{g}}$ & $\begin{array}{l}\hat{\sigma} \\
\stackrel{n}{n} \\
\stackrel{n}{\Xi}\end{array}$ & $\underset{m}{\stackrel{n}{=}}$ \\
\hline 志 & $\stackrel{⿱}{r}$ & $\stackrel{?}{?}$ & $\vec{r}$ & $\underset{\infty}{\infty}$ & $\stackrel{\Upsilon}{r}$ & $\stackrel{\infty}{0}$ & $\hat{\sigma}$ & $\begin{array}{l}\infty \\
\infty \\
\infty\end{array}$ & $\stackrel{?}{r}$ & $\stackrel{⿱ r}{r}$ & $\begin{array}{l}\infty \\
\infty\end{array}$ & $\stackrel{\infty}{\sim}$ & $\stackrel{\circ}{r}$ & $\stackrel{\infty}{0}$ \\
\hline 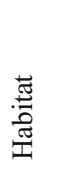 & $\begin{array}{l}\frac{0}{0} \\
\frac{0}{n} \\
\frac{2}{0} \\
0 \\
0\end{array}$ & $\frac{0}{\frac{0}{2}}$ & 总 & 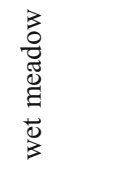 & 芯 & $\begin{array}{l}\frac{0}{0} \\
\frac{0}{0} \\
\text { 竞 } \\
\frac{0}{0} \\
\vdots\end{array}$ & 芯 & $\frac{0}{\frac{0}{0}}$ & $\frac{0}{\frac{0}{2}}$ & $\frac{0}{\frac{0}{0}}$ & $\frac{\grave{a}}{\frac{0}{\omega}}$ & $\frac{0}{\frac{0}{2}}$ & 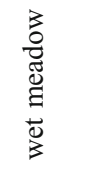 & $\begin{array}{l}\frac{0}{0} \\
\frac{0}{0} \\
\frac{\overrightarrow{0}}{0} \\
0 \\
0\end{array}$ \\
\hline 离 & 띠 & 띠 & $\sqrt[w]{\mathfrak{2}}$ & 0 & 竞 & 디 & 0 & $\sum_{n=1}^{3}$ & is & is & $\sum_{n}^{3}$ & is & 0 & 山 \\
\hline$\frac{\ddot{\partial}}{\tilde{\omega}}$ & $\approx$ & 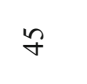 & $\ddot{\sim}$ & 0 & in & 尺े & 0 & $\stackrel{m}{\text { r }}$ & in & in & ్ల & $\cong$ & 0 & 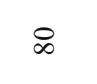 \\
\hline 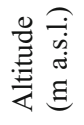 & 号 & \&్రి & $\begin{array}{l}\stackrel{0}{ } \\
\text { तn }\end{array}$ & & ঃి & $\stackrel{\circ}{\stackrel{ }{d}}$ & ڤn & 尽 & $\underset{\sim}{\stackrel{O}{d}}$ & ષ્તે & 尽 & ષ્તે & $\underset{\sim}{\stackrel{7}{d}}$ & 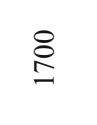 \\
\hline 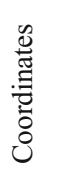 & 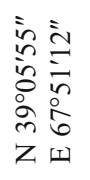 & 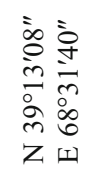 & 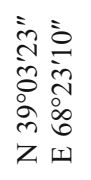 & 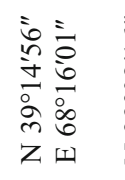 & 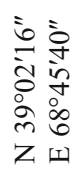 & 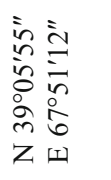 & 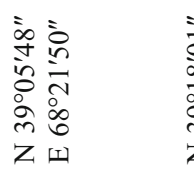 & 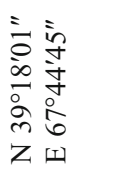 & 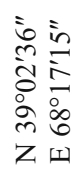 & 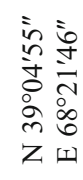 & 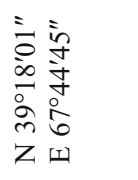 & 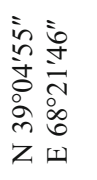 & 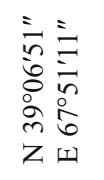 & 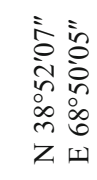 \\
\hline 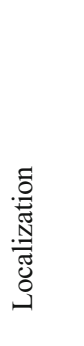 & 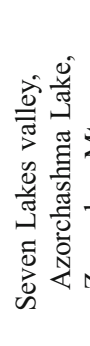 & 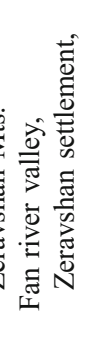 & 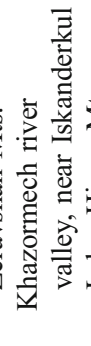 & 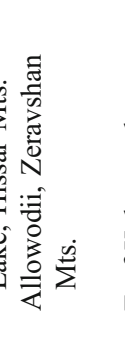 & 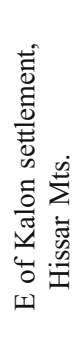 & 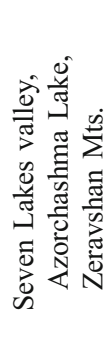 & 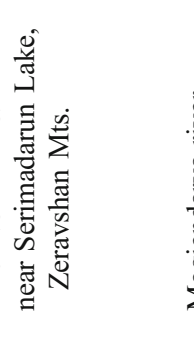 & 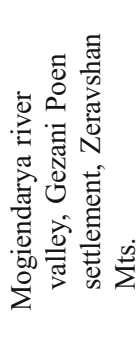 & 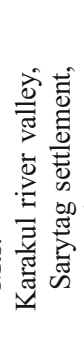 & 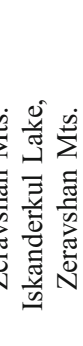 & 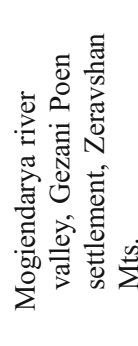 & 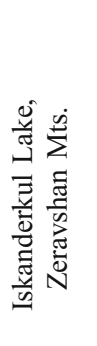 & 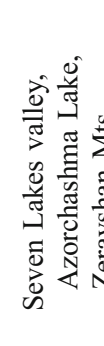 & 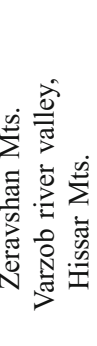 \\
\hline 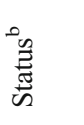 & $\begin{array}{l}\vec{j} \\
\overline{0} \\
\dot{1} \\
\overline{\vec{n}}\end{array}$ & $\dot{\tilde{g}}$ & $\begin{array}{l}\vec{j} \\
\overline{0} \\
\dot{1} \\
\vec{\omega}\end{array}$ & 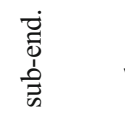 & $\vec{\Xi}$ & ت्ठ & $\vec{\Xi}$ & वृं & $\begin{array}{l}\overrightarrow{0} \\
\overline{0} \\
\dot{1} \\
\vec{\omega}\end{array}$ & घं & $\begin{array}{l}\overrightarrow{0} \\
\overline{0} \\
\dot{1} \\
\vec{\omega}\end{array}$ & 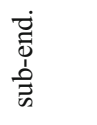 & एँ & ப் \\
\hline 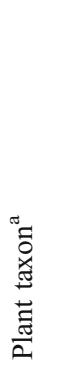 & 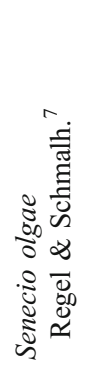 & 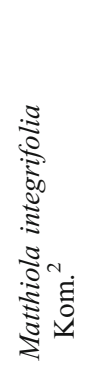 & 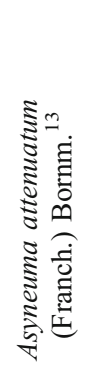 & 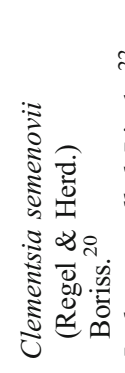 & 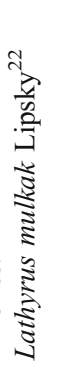 & 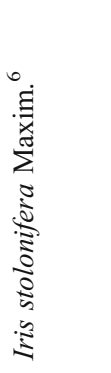 & 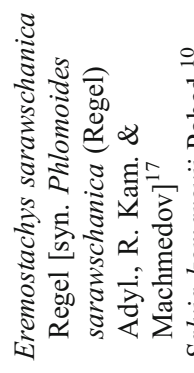 & 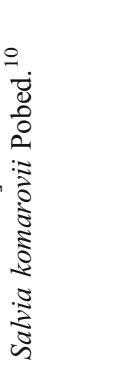 & 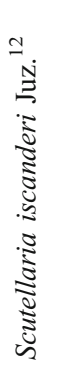 & 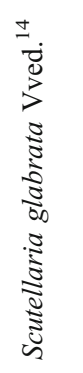 & 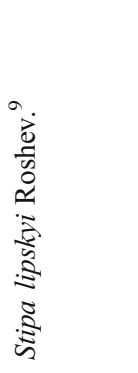 & 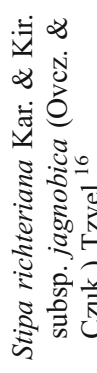 & 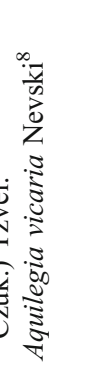 & 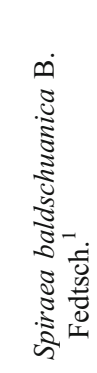 \\
\hline$\frac{\vec{z}}{\bar{z}}$ & 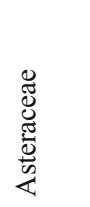 & 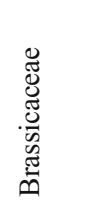 & 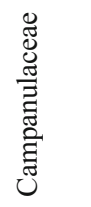 & 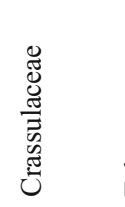 & 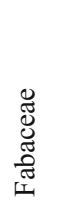 & 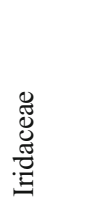 & 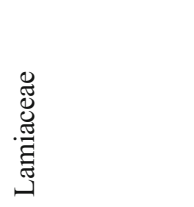 & & & & 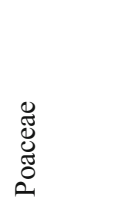 & & 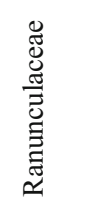 & $\begin{array}{l}\mathscr{\Xi} \\
\mathscr{\Xi} \\
\mathscr{\varpi} \\
\stackrel{0}{2}\end{array}$ \\
\hline
\end{tabular}


parameters evaluated were: mycorrhizal frequency (F), relative mycorrhizal root length $(\mathrm{M})$ and relative arbuscular richness (A). An estimate of mycorrhizal frequency ( $\mathrm{F} \%)$ is given as the ratio between root fragments colonized by AMF mycelium and the total number of root fragments analyzed. The relative mycorrhizal root length ( $\mathrm{M} \%)$ is an estimate of the amount of root cortex that is mycorrhizal relative to the whole root system under study. The relative arbuscular richness (A\%) is an estimate of arbuscule abundance in the whole root system under study (Trouvelot et al. 1986).

DSE colonization was identified on the basis of regularly septate hyphae, usually dark pigmented, with facultatively occurring sclerotia (Read and Haselwandter 1981; Haselwandter and Read 1980; Jumpponen 2001). The frequency of DSE mycelium occurrence in the roots ( $\mathrm{F}_{\mathrm{DSE}} \%$ ) was estimated as detailed for $\mathrm{AMF}$ in the foregoing. In addition, the frequency of the occurrence of sporangia of fungi from the genus Olpidium $\left(\mathrm{F}_{\mathrm{Olp}} \%\right)$ was assessed (Agrios 2005; Webster and Weber 2007; Zubek and Błaszkowski 2009).

\subsection{AMF species diversity}

\subsubsection{Establishment of the trap cultures}

Soil samples surrounding the plants' roots were excavated in 16 locations (Table 1). For the establishment of each trap culture, approximately $100 \mathrm{~g}$ of air-dried soil was placed into $9 \times 12.5 \mathrm{~cm}, 500 \mathrm{ml}$ plastic pots containing autoclaved, commercially available, coarse-grained sand, the proportions of the grains being $1.0-10.0 \mathrm{~mm}$ in diam. $-80.50 \%$; $0.1-1.0 \mathrm{~mm}$ in diam. $-17.28 \%$; and grains $<0.1 \mathrm{~mm}$ in diam. $-2.22 \%$. Plantago lanceolata L., a mycorrhizal plant species with extensive root system and a good tolerance to growing conditions in a greenhouse, was used as the host plant.

\subsubsection{Spore isolation and identification}

Eleven months after establishment of the trap cultures, AMF spores were extracted using the wet sieving and decanting method (Gerdemann and Nicolson 1963). The morphological properties of the spores and their subcellular structures were determined in material mounted on a slide in a drop of polyvinyl alcohol/lactic acid/glycerol (PVLG) and in a mixture of PVLG/Melzer's reagent $(4: 1, \mathrm{~V} / \mathrm{v})$ (Omar et al. 1979). Observation of AMF spore characteristic was performed by means of an Olympus BX51 light microscope. The slides containing the isolated spores have been deposited in the slide collection of the Department of Plant Protection, at the West Pomeranian University of Technology in Szczecin. 


\section{Results}

\subsection{Fungal root endophytes}

\subsubsection{Arbuscular mycorrhizal fungi}

Arbuscular mycorrhizae with arbuscules, which are the structural and functional criterion of the symbiosis, were observed in 15 out of 16 species examined (Table 2). Coarse AMF (hyphae diameter above $2 \mu \mathrm{m}$ ) dominated in the roots of these plants. The fine endophyte, usually considered as being Glomus tenue and characterized by mycelium of ca. $1 \mu \mathrm{m}$ in diameter, small vesicles or swellings and fan-shaped branches, was found sporadically only in Clementsia semenovii and was rarely observed to form arbuscules in this plant. The abundance of AMF in the roots varied widely with particular taxa (Table 2). The highest AMF colonization was found in Salvia komarovii $(M=91.7 \%)$, which was also characterized by high arbuscule richness $(A=88.6 \%)$. The lowest AMF colonization was observed in Scutellaria glabrata $(M=36.1 \%)$. AMF structures were found to be absent only in the roots of Matthiola integrifolia, the representative of Brassicaceae (Table 2).

The plants examined from the Asteraceae, Fabaceae, Lamiaceae, Rosaceae and Violaceae families showed Arumtype colonization, in which AMF hyphae were found in the intercellular spaces of the root cortex, forming arbuscules terminally, one per cortical cell (Fig. 1a-c). The representatives of the families Crassulaceae, Ranunculaceae and Rubiaceae were of the Paris morphology, in which neighbouring cortical cells contained hyphal coils and arbusculate coils, without hyphae in the intercellular spaces (Fig. 1d-f). Both Arum and Paris, and Paris and intermediate AM colonization was found among the species of Poaceae, and Campanulaceae and Iridaceae, respectively (Table 2).

\subsubsection{Dark septate endophytes}

DSE accompanied AMF in the roots of ten species (Table 2). The frequency of DSE occurrence in the roots $\left(\mathrm{F}_{\mathrm{DSE}}\right)$ was generally low. The exception was Spiraea baldshuanica, where $\mathrm{F}_{\mathrm{DSE}}$ was above $60 \%$. Nevertheless, in all cases, the percentage of root colonization was low (data not shown). Single hyphae of different diameters were found in the outer cortex and rhizodermis (Fig. 1g-h). The mycelium was brownish or, rarely, stained with aniline blue. Single DSE hyphae were also detected on the root surface and/or between the root hairs of several specimens. In the old and probably dead roots of several species, which were not included in the assessments of AMF and DSE colonization, DSE mycelium was more abundant.

\subsubsection{Olpidium spp.}

The sporangia of Olpidium spp., which stained with aniline blue, were found sporadically inside Eremostachys sarawschanica, Matthiola integrifolia and Scutellaria iskanderi root epidermal cells (Fig. 1i). Both the frequency of the occurrence of these structures in the roots being analyzed (Table 2) and the percentage of root infection (data not shown) were low.

\subsection{AMF species diversity}

The spores of 7 AMF species from five families were extracted from the trap cultures established with the soils collected from under the endemic plant species being studied (Table 3). AMF spores were found in all the pots, indicating that the propagules of Glomeromycota were present in the soil of all the plants being examined, including Matthiola integrifolia, which was found to be non-mycorrhizal in this study. The spores of Funneliformis constrictum were most frequently isolated from the pot cultures. In contrast, Claroideoglomus claroideum, Paraglomus majewskii and Racocetra fulgida were detected in single cultures. Additionally, one morphotype with glomoid, small, pale yellow spores of an unknown generic position was isolated (Table 3).

\section{Discussion}

The use of soil microorganism consortia, especially arbuscular mycorrhizal fungi (AMF), to support plant growth has been proposed for the conservation programmes of rare, endemic and endangered taxa (Barroetavena et al. 1998; Gemma et al. 2002; Panwar and Vyas 2002; Turnau and Haselwandter 2002; Fisher and Jayachandran 2002, 2005; Zubek et al. 2008, 2009; Bothe et al. 2010). In both the maintenance of species composition and the cultivation and reintroduction of valuable taxa, the knowledge of plant interactions below ground can be essential (Eriksen et al. 2002; Turnau and Haselwandter 2002; Bothe et al. 2010). In this research, we recognized, to the best of our knowledge for the first time, the mycorrhizal status of 16 high priority plants, i.e. species considered as endemic and sub-endemic to one of the world's biodiversity hotspots. Moreover, the genera Asyneuma, Clementsia and Eremostachys were studied for the first time in respect of fungal root colonization. These studies provide important basic information on the biology and ecology of these plant species and may facilitate the potential use of AMF in endeavours aimed at their conservation. However, this research must be followed up by investigation into plantfungus interactions and possible dependency. Only on the 


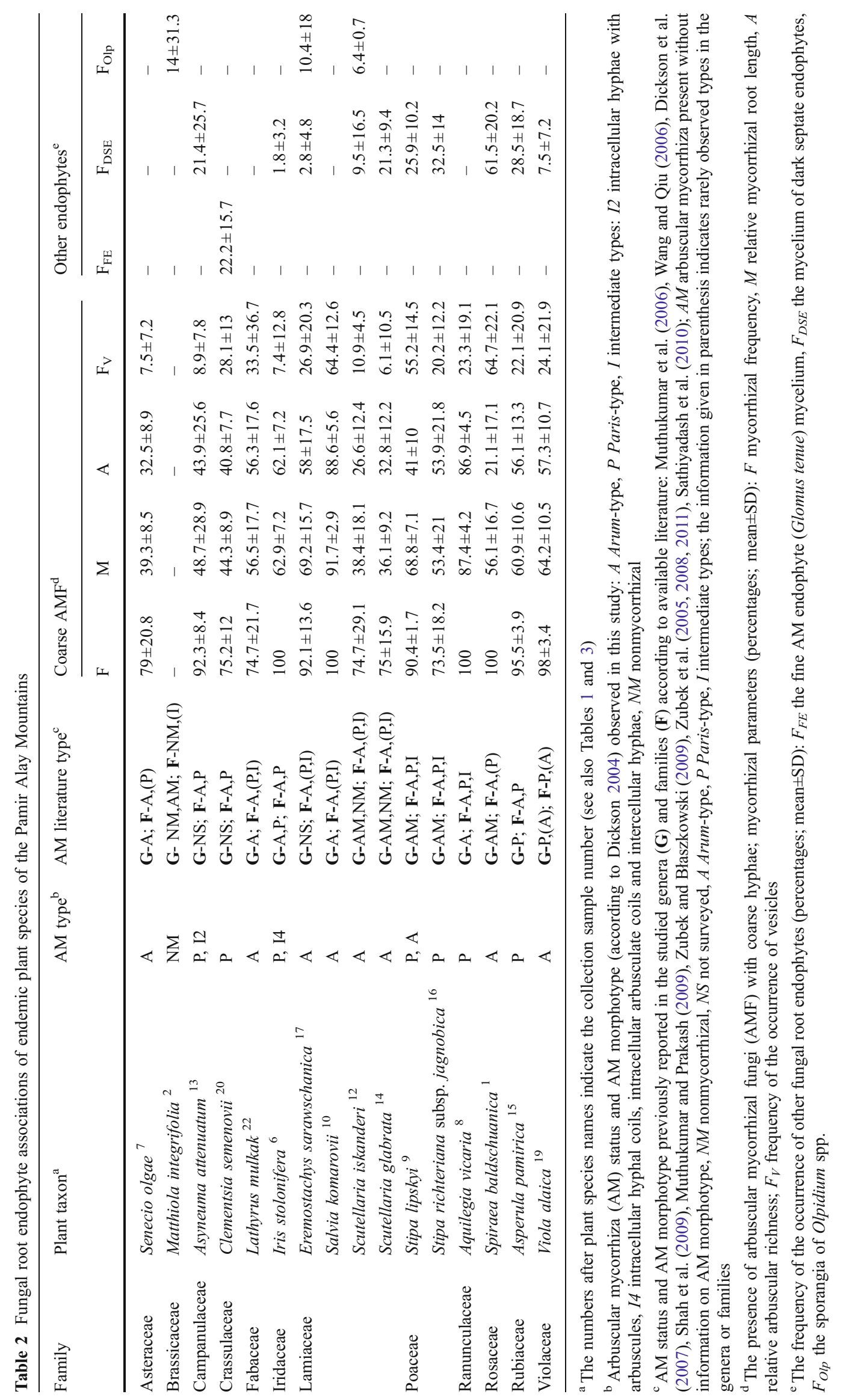



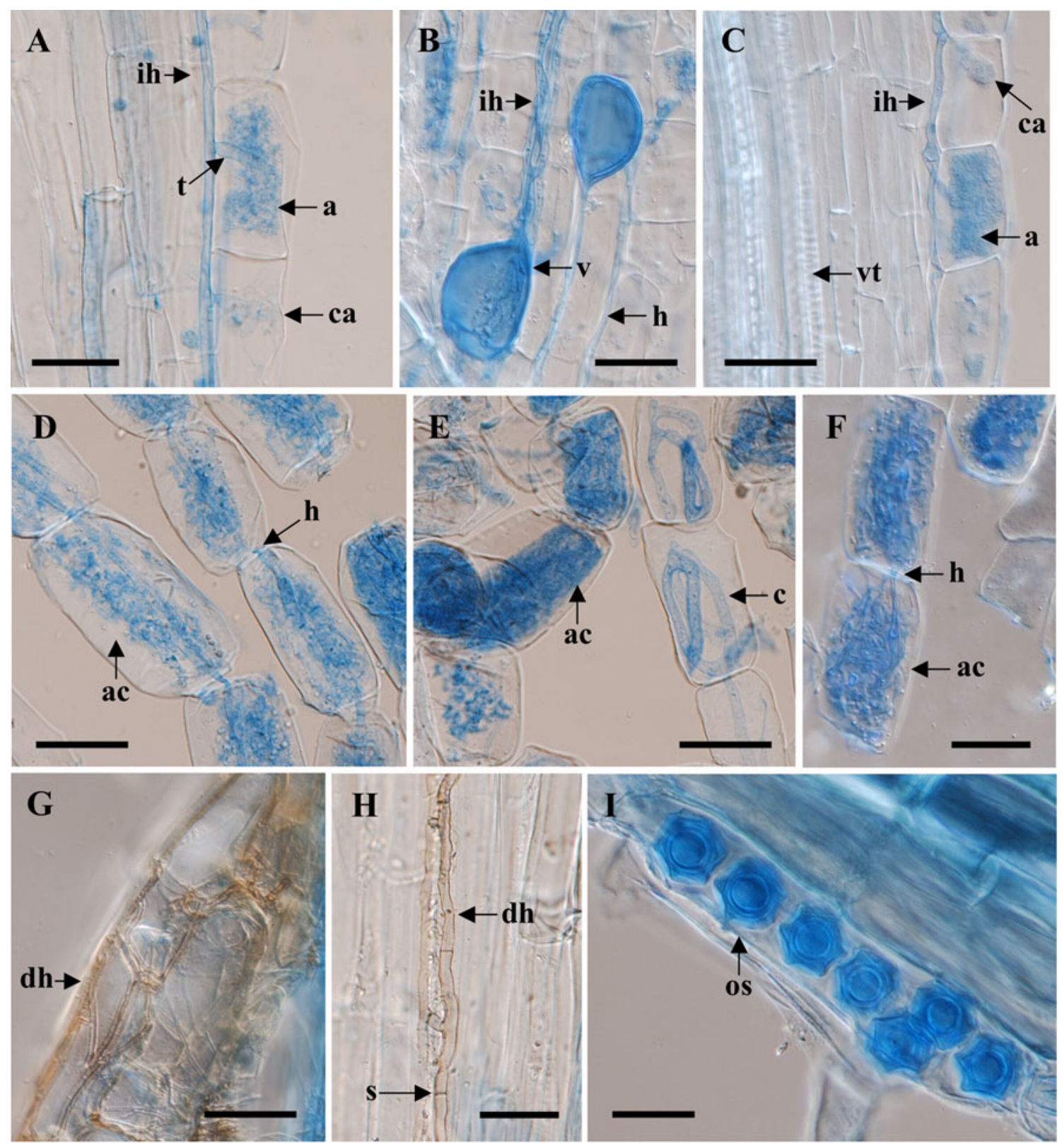

Fig. 1 a-i Fungal root endophytes in the roots of endemic plants of the Pamir Alay Mountains; the light micrographs in Nomarski interference contrast optics; scale bars - $25 \mu \mathrm{m}$; a-f - Arbuscular mycorrhizal fungi (AMF) with coarse hyphae in the root cortex of Senecio olgae (a), Scutellaria iskanderi (b), Eremostachys sarawschanica (c) (Arum morphotype of AM), Aquilegia vicaria (d, e) and Stipa richteriana subsp. jagnobica (f) (Paris morphotype); a terminally formed arbuscules, ac arbuscules formed on coils (arbus-

basis of detailed field and experimental research can successful methods for the application of AMF in conservation programmes be developed.

In the present study, the AM morphotype was reported for the first time, to the best of our knowledge, for all the species analyzed and for the genera Asyneuma, Clementsia, Eremostachys, Scutellaria, Spiraea and Stipa. Plants from culate coils), $c$ coils, $c a$ collapsing arbuscules, $h$ AMF hyphae growing intracellularly from cell to cell, ih hyphae growing intercellularly, $t$ arbuscule trunk, $v$ vesicle formed between cortical cells, $v t$ vascular tissue. g-h - Dark septate endophyte (DSE) mycelium in the outer root cortex of Asperula pamirica (g) and Stipa lipskyi (h); $d h$ DSE hyphae, $s$ septa. i - The sporangia of Olpidium sp. $(o s)$ in the rhizodermal cell of Matthiola integrifolia

the Asteraceae, Fabaceae, Lamiaceae, Rosaceae and Violaceae families showed Arum-type colonization, the representatives of the families Crassulaceae, Ranunculaceae and Rubiaceae were of the Paris morphology, and both Arum and Paris, and Paris and intermediate AM colonization was found among the representatives of Poaceae, and Campanulaceae and Iridaceae, respectively. The results are in 
Table 3 Arbuscular mycorrhizal fungi (Glomeromycota) isolated from trap cultures established with the soils collected from under the endemic plant species of the Pamir Alay Mountains (see Section 2)

\begin{tabular}{|c|c|}
\hline Family & Fungal species \\
\hline Archaeosporaceae & Archaeospora trappei (R.N. Ames \& Linderman) J.B. Morton \& D. Redecker 7,10,20 \\
\hline Gigasporaceae & Racocetra fulgida (Koske \& C. Walker) Oehl, F.A. Souza \& Sieverd. ${ }^{7}$ \\
\hline Claroideoglomeraceae & $\begin{array}{l}\text { Claroideoglomus claroideum (N.C. Schenck \& G.S.Sm.) C. Walker \& A. Schüßler }{ }^{2} \\
\text { Claroideoglomus drummondii (Blaszk. \& C. Renker) C. Walker \& A. Schüßler }{ }^{14,22}\end{array}$ \\
\hline Glomeraceae & $\begin{array}{l}\text { Funneliformis constrictum (Trappe) C. Walker \& A. Schüßler } 1,6,7,8,9,10,12,13,14,16,17,19,20,22 \\
\text { Funneliformis mosseae (T.H. Nicolson \& Gerd.) C. Walker \& A. Schüßler } 9,14,15,17,22\end{array}$ \\
\hline Unknown & Morphotype with glomoid, small, pale yellow spores of unknown generic position ${ }^{20}$ \\
\hline Paraglomeraceae & Paraglomus majewskii Błaszk. \& Kovács sp. ined. ${ }^{2}$ \\
\hline
\end{tabular}

Fungal species and family names are after Schüßler and Walker (2010). The numbers after the species names indicate the collection sample number (see Table 1)

accordance with other studies, where these morphotypes have also been observed among other representatives of the investigated genera and families. The exception was Aquilegia vicaria (Ranunculaceae), in which the Paris morphology of AM was found, whereas in a previous report, other species from this genus, A. vulgaris, was observed to form the Arum-type. Nevertheless, Arum, Paris and intermediate types have been documented in the Ranunculaceae family (see Table 2). It is known that AM morphology may depend on the host plant and fungal identity and that different environmental factors may have an impact on the AM pattern of root colonization (Cavagnaro et al. 2001; Dickson 2004; Yamato 2004; Kubota et al. 2005; Dickson et al. 2007; Smith and Read 2008). In view of the aforementioned findings, different patterns of AM colonization may be observed in the same plant genus or even species.

Among the species under study, AMF colonization was found to be absent only in Matthiola integrifolia (Brassicaceae). This observation is, however, not surprising, as the family has been considered as generally nonmycorrhizal (Wang and Qiu 2006). The absence of AMF colonization in Brassicaceae species has usually been explained by the presence of chemical barriers, low root exudation, the lack of signaling compounds and root anatomy (DeMars and Boerner 1996). Nevertheless, AM structures have been observed among some representatives of Brassicaceae, indicating that some species may form AM in particular environmental conditions (DeMars and Boerner 1995, 1996; Orłowska et al. 2002; Regvar et al. 2003; Wang and Qiu 2006; Shah et al. 2009). Among these taxa, the other species of Matthiola genus, M. incana, was found to be colonized by AMF; however, no arbuscules were observed in the roots, which suggests that AM was nonfunctional (DeMars and Boerner 1995).

Seven AMF species were revealed in the trap cultures established with soils of the investigated endemic plants of the Pamir Alay Mountains. This is the first record of AMF species in this area. With the exception of Paraglomus majewskii, the other species have frequently been isolated from different soils and have a worldwide distribution (http://www.zor.zut.edu.pl/Glomeromycota/). Although not reported in the literature to date, P. majewskii is also one of the most commonly occurring AMF in the world (Błaszkowski et al. 2011). The previous omission of P. majewskii from the scientific record probably resulted from the fact that its spores are colorless, small and delicate and may thus either have been overlooked or absent, owing to their complete decomposition by soil parasites (Lee and Koske 1994), or possibly because it sporulates seasonally, rarely or not at all in the field (Gemma et al. 1989; Stutz and Morton 1996). Growing successive pot trap cultures frequently stimulates sporulation of AMF and reveals species that produce spores either seasonally or not at all in field conditions (Stutz and Morton 1996).

Additionally, we found one morphotype, the glomoid, small, pale yellow spores of which do not fit the morphology of any known AMF. At present, AMF producing typical glomoid spores, i.e. spores arising identically and having subcellular structure similar to those of the genus Glomus sensu Schüßler and Walker (2010), are accommodated in ten genera. In most cases, the spore morphology of these species does not indicate their generic affiliation unambiguously. Thus, it is difficult or impossible to classify a given fungus with typical glomoid spores to a proper genus based solely on its morphology. This may, however, be done by using molecular tools. The morphotype is now being grown in single-species cultures in order to obtain a sufficient number of spores for morphological and molecular analyses.

Dark septate endophytes (DSE) are frequently encountered in roots of numerous plant taxa, including endemic and endangered ones (Fuchs and Haselwandter 2004; Muthukumar et al. 2006; Zubek et al. 2008; Lugo et al. 
2009; Sathiyadash et al. 2010). The effects of these endophytes on plants are variable and, like in AM symbioses, may depend on the host species, fungal taxa or strains, and environmental conditions (Haselwandter and Read 1982; Jumpponen 2001; Wu and Guo 2008; Upson et al. 2009; $\mathrm{Wu}$ et al. 2010; Andrade-Linares et al. 2011; Mandyam et al. 2011; Newsham 2011). DSE produce in roots hyphae and sclerotia that cannot be regarded as specialized interfaces for the transfer of nutrients between plant and fungus. Therefore, these fungi probably do not influence plant performance through direct contact with roots (Newsham 2011). Nevertheless, as suggested by Andrade-Linares et al. (2011) and Mandyam et al. (2011), the effects of DSE on plants may be related to the intensity of their colonization of roots. Several mechanisms might explain the positive effects of these fungi on plant growth, including enhanced protection from soil pathogens, the synthesis of hormones or the mineralization by DSE of organic compounds in soil (Mandyam and Jumpponen 2005; Wu et al. 2010; Newsham 2011). Recently published meta-analysis showed that the positive role of DSE in the stimulation of plant performance has been especially pronounced in soil conditions with nitrogen being present mostly in organic form which supports the hypothesis that these fungi may enhance plant growth making inorganic $\mathrm{N}$ more freely available to roots (Newsham 2011). The situation when inorganic $\mathrm{N}$ is in short supply to roots occurs at higher altitudes due to the slow decomposition of organic matter at low temperature. Similarly to AMF, DSE may play an important role in improving plant performance, especially in the case of plants which are rarely or not colonized by Glomeromycota fungi. On the basis of our observations, however, it is not possible both to assess the influence of DSE on the plants of the Pamir Alay Mountains under study and answer the question as to whether the presence of DSE mycelia and the intensity of their abundance in the living roots play a role in these interactions. In order to reveal the nature of these associations, further research under experimental conditions is necessary. Such studies were conducted by $\mathrm{Wu}$ and Guo (2008) and Wu et al. (2010). The authors found that DSE colonize the roots of Saussurea involucrata (Asteraceae), an endangered and medicinal plant species found in the Chinese mountains. In a laboratory experiment, the seedlings of this valuable species were inoculated with DSE strains previously isolated from $S$. involucrata roots; the plants displayed enhanced growth due to DSE inoculation. These findings create the possibility of DSE application in the cultivation of S. involucrata for both medicinal and conservation purposes (Wu and Guo 2008; $\mathrm{Wu}$ et al. 2010).

Among fungal root endophytes observed in the material under study, we also found sporangia of Olpidium
(Chytridiomycota) in the epidermal cells of three plant species. Fungi of the Olpidium genus are symptomless root parasites and are also vectors of plant viruses (VerchotLubicz 2003; Agrios 2005; Webster and Weber 2007). Their role as plant pathogens in the taxa investigated in this study is probably minor, as only single sporangia of these endophytes were observed. Nevertheless, the monitoring of Olpidium presence in roots of rare and endangered plant species seems to be important owing to the potential ability of these endophytes to spread soilborne viral plant diseases (Verchot-Lubicz 2003).

Acknowledgements We are grateful to two anonymous Reviewers for their valuable comments on the manuscript. The present research was financially supported by the funds of the Institute of Botany, Jagiellonian University.

Open Access This article is distributed under the terms of the Creative Commons Attribution Noncommercial License which permits any noncommercial use, distribution, and reproduction in any medium, provided the original author(s) and source are credited.

\section{References}

Agrios GN (2005) Plant pathology, 5th edn. Elsevier Academic Press, Amsterdam

Andrade-Linares DR, Grosch R, Restrepo S, Krumbein A, Franken P (2011) Effects of dark septate endophytes on tomato plant performance. Mycorrhiza 21:413-422

Barroetavena C, Gisler SD, Luoma DL, Meinke RJ (1998) Mycorrhizal status of the endangered species Astragalus applegatei Peck as determined from a soil bioassay. Mycorrhiza 8:117-119

Błaszkowski J, Kovács GM, Gáspár BK, Balázs TK, Buscot F, Ryszka P (2011) The arbuscular mycorrhizal Paraglomus majewskii sp. nov. represents a distinct basal lineage in Glomeromycota. Mycologia (in press)

Bothe H, Turnau K, Regvar M (2010) The potential role of arbuscular mycorrhizal fungi in protecting endangered plants and habitats. Mycorrhiza 20:445-457

Cavagnaro TR, Gao L-L, Smith FA, Smith SE (2001) Morphology of arbuscular mycorrhizas is influenced by fungal identity. New Phytol 151:469-475

Czerepanov SK (1995) Plantae Vasculares URSS. Nauka

DeMars BG, Boerner REJ (1995) Arbuscular mycorrhizal development in three crucifers. Mycorrhiza 5:405-408

DeMars BG, Boerner REJ (1996) Vesicular-arbuscular mycorrhizal development in the Brassicaceae in relation to plant life span. Flora 191:179-189

Dickson S (2004) The Arum-Paris continuum of mycorrhizal symbioses. New Phytol 163:187-200

Dickson S, Smith A, Smith SE (2007) Structural differences in arbuscular mycorrhizal symbioses: more than 100 years after Gallaud, where next? Mycorrhiza 17:375-393

Dodd JC, Boddington CL, Rodriguez A, González-Chávez C, Mansur I (2000) Mycelium of arbuscular mycorrhizal fungi (AMF) from different genera: form, function and detection. Plant Soil 226:131-151

Eriksen M, Bjureke KE, Dhillion SS (2002) Mycorrhizal plants of traditionally managed boreal grasslands in Norway. Mycorrhiza $12: 117-123$ 
Fisher JB, Jayachandran K (2002) Arbuscular mycorrhizal fungi enhance seedling growth in two endangered plant species from South Florida. Int J Plant Sci 163:559-566

Fisher JB, Jayachandran K (2005) Presence of arbuscular mycorrhizal fungi in South Florida native plants. Mycorrhiza 15:580-588

Fuchs B, Haselwandter K (2004) Red list plants: colonization by arbuscular mycorrhizal fungi and dark septate endophytes. Mycorrhiza 14:277-281

Gemma JN, Koske RE, Carreiro M (1989) Seasonal dynamics of selected species of VA mycorrhizal fungi in a sand dune. Mycol Res 92:317-321

Gemma JN, Koske RE, Habte M (2002) Mycorrhizal dependency of some endemic and endangered Hawaiian plant species. Am J Bot 89:337-345

Gerdemann JW, Nicolson TH (1963) Spores of mycorrhizal Endogone species extracted from soil by wet sieving and decanting. Trans Br Mycol Soc 46:235-244

Giam X, Bradshaw CJA, Tan HTW, Sodhi NS (2010) Future habitat loss and the conservation of plant biodiversity. Biol Conserv 143:1594-1602

Haselwandter K, Read DJ (1980) Fungal associations of roots of dominant and sub-dominant plants in high-alpine vegetation systems with special reference to mycorrhiza. Oecologia 45:57-62

Haselwandter K, Read DJ (1982) The significance of a root-fungus association in two Carex species of high-alpine plant communities. Oecologia 53:352-354

Jumpponen A (2001) Dark septate endophytes — are they mycorrhizal? Mycorrhiza 11:207-211

Kubota M, McGonigle TP, Hyakumachi M (2005) Co-occurrence of Arum- and Paris-type morphologies of arbuscular mycorrhizae in cucumber and tomato. Mycorrhiza 15:73-77

Lamoreux JF, Morrison JC, Ricketts TH, Olson DM, Dinerstein E, Knight MW, Shugart HH (2006) Global test of biodiversity concordance and the importance of endemism. Nature 440:212-214

Lee PJ, Koske RE (1994) Gigaspora gigantea: parasitism of spores by fungi and actinomycetes. Mycol Res 98:458-466

Lugo MA, Molina MG, Crespo EM (2009) Arbuscular mycorrhizas and dark septate endophytes in bromeliads from South American arid environment. Symbiosis 47:17-21

Malcolm JR, Liu C, Neilson RP, Hansen L, Hannah L (2006) Global warming and extinctions of endemic species from biodiversity hotspots. Conserv Biol 20:538-548

Mandyam K, Jumpponen A (2005) Seeking the elusive function of the root-colonising dark septate endophytic fungi. Stud Mycol 53:173-189

Mandyam K, Fox C, Jumpponen A (2011) Septate endophyte colonization and host responses of grasses and forbs native to a tallgrass prairie. Mycorrhiza. doi:10.1007/s00572-011-0386-y

Mittermeier RA, Gil PR, Hoffman M, Pilgrim J, Brooks T, GoettschMittermeier C, Lamoreux J, da Fonseca GAB (2005) Hotspots revisited: earth's biologically richest and most threatened terrestrial ecoregions. Conservation International, Washington DC

Muthukumar T, Prakash S (2009) Arbuscular mycorrhizal morphology in crops and associated weeds in tropical agro-ecosystems. Mycoscience 50:233-239

Muthukumar T, Senthilkumar M, Rajangam M, Udaiyan K (2006) Arbuscular mycorrhizal morphology and dark septate fungal associations in medicinal and aromatic plants of Western Ghats, Southern India. Mycorrhiza 17:11-24

Myers N, Mittermeier RA, Mittermeier CG, de Fonseca GAB, Kent J (2000) Biodiversity hotspots for conservation priorities. Nature 403:853-858

Newsham KK (2011) A meta-analysis of plant responses to dark septate root endophytes. New Phytol. doi:10.1111/j.1469-137.2010.03611.x

Nobis M (2011) Stipa $\times$ brozhiana (Poaceae) nothosp. nov. from the western Pamir Alai Mts (middle Asia) and taxonomical notes on Stipa $\times$ tzvelevii. Nord J Bot 29:458-464
Nowak A, Nobis M (2010) Tentative list of endemic vascular plants of the Zeravshan Mts in Tajikistan: distribution, habitat preferences and conservation status of species. Biodivers Res Conserv 19:65-80

Nowak A, Nowak S, Nobis M (2011) Distribution patterns, ecological characteristic and conservation status of endemic plants of Tadzhikistan -a global hotspot of diversity. J Nat Conserv 19:296-305

Omar MB, Bolland L, Heather WA (1979) A permanent mounting medium for fungi. Bull Br Mycol Soc 13:13-32

Orłowska E, Zubek S, Jurkiewicz A, Szarek-Łukaszewska G, Turnau K (2002) Influence of restoration on arbuscular mycorrhiza of Biscutella laevigata L. (Brassicaceae) and Plantago lanceolata L. (Plantaginaceae) from calamine spoil mounds. Mycorrhiza 12:153-160

Panwar J, Vyas A (2002) AM fungi: A biological approach towards conservation of endangered plants in Thar desert, India. Curr Sci India 82:576-578

Phillips J, Hayman DS (1970) Improved procedures for clearing roots and staining parasitic and vesicular-arbuscular mycorrhizal fungi for rapid assessment of infection. Trans Br Mycol Soc 55:158-161

Rasulova MR (1991) Flora Tadzhikskoi SSR. T. 10. Slozhonotsvetnye. Leningrad, Nauka

Read DJ, Haselwandter K (1981) Observations on the mycorrhizal status of some alpine plant communities. New Phytol 88:341-352

Regvar M, Vogel K, Irgel N, Wraber T, Hildebrandt U, Wilde P, Bothe H (2003) Colonization of pennycresses (Thlaspi spp.) of the Brassicaceae by arbuscular mycorrhizal fungi. J Plant Physiol 160:615-625

Safarov N (2003) National strategy and action plan on conservation and sustainable use of biodiversity. Governmental Working Group of the Republic of Tajikistan, Dushanbe

Sathiyadash K, Muthukumar T, Uma E (2010) Arbuscular mycorrhizal and dark septate endophyte fungal associations in South Indian grasses. Symbiosis 52:21-32

Schüßler A, Walker C (2010) The Glomeromycota. A species list with new families and new genera. Schüßler A., Walker C. Gloucester, Published in libraries at Royal Botanic Garden Edinburgh, Kew, Botanische Staatssammlung Munich, and Oregon State University

Shah MA, Reshi ZA, Khasa D (2009) Arbuscular mycorrhizal status of some Kashmir Himalayan alien invasive plants. Mycorrhiza 20:67-72

Smith SE, Read DJ (2008) Mycorrhizal symbiosis, 3rd edn. Academic, London

Stutz JC, Morton JB (1996) Successive pot cultures reveal high species richness of arbuscular mycorrhizal fungi in arid ecosystems. Can J Bot 74:1883-1889

Thippayarugs S, Bansal M, Abbott LK (1999) Morphology and infectivity of fine endophyte in mediterranean environment. Mycol Res 103:1369-1379

Trouvelot A, Kough JL, Gianinazzi-Pearson V (1986) Mesure du taux de mycorhization VA d'un systeme radiculaire. Recherche de methodes d'estimation ayant une signification fonctionnelle. In: Gianinazzi-Pearson V, Gianinazzi S (eds) Physiological and genetical aspects of mycorrhizae. INRA, Paris, pp. 217-221, http://www2.dijon.inra.fr/mychintec/Protocole/Workshop Procedures.html

Turnau K, Haselwandter K (2002) Arbuscular mycorrhizal fungi, an essential component of soil microflora in ecosystem restoration. In: Gianinazzi S, Schüepp H, Barea JM, Haselwandter $\mathrm{K}$ (eds) Mycorrhizal technology in agriculture. From genes to mycorrhiza application. Birkhauser Verlag, Switzerland, pp 137-149

Upson R, Read DJ, Newsham KK (2009) Nitrogen form influences the response of Deschampsia antarctica to dark septate root endophytes. Mycorrhiza 20:1-11 
Verchot-Lubicz J (2003) Soilborne viruses: advances in virus movement, virus induced gene silencing, and engineered resistance. Physiol Mol Plant Pathol 62:55-63

Wang B, Qiu YL (2006) Phylogenetic distribution and evolution of mycorrhizas in land plants. Mycorrhiza 16:299-363

Webster J, Weber RWS (2007) Introduction to fungi, 3rd edn. Cambridge University Press, Cambridge

Wu L, Guo S (2008) Interaction between an isolate of dark-septate fungi and its host plant Saussurea involucrata. Mycorrhiza 18:79-85

Wu L, Lv Y, Meng Z, Chen J, Guo S (2010) The promoting role of an isolate of dark-septate fungus on its host plant Saussurea involucrata Kar. et Kir. Mycorrhiza 20:127-135

Yamato M (2004) Morphological types of arbuscular mycorrhizal fungi in roots of weeds on vacant land. Mycorrhiza 14:127-131
Zubek S, Błaszkowski J (2009) Medicinal plants as hosts of arbuscular mycorrhizal fungi and dark septate endophytes. Phytochem Rev 8:571-580

Zubek S, Turnau K, Błaszkowski J (2005) Arbuscular mycorrhiza of plants from the Mountain Botanical Garden in Zakopane. Acta Mycol 40:25-41

Zubek S, Turnau K, Błaszkowski J (2008) Arbuscular mycorrhiza of endemic and endangered plants from the Tatra Mts. Acta Soc Bot Pol 77:149-156

Zubek S, Turnau K, Tsimilli-Michael M, Strasser RJ (2009) Response of endangered plant species to inoculation with arbuscular mycorrhizal fungi and soil bacteria. Mycorrhiza 19:113-123

Zubek S, Błaszkowski J, Mleczko P (2011) Arbuscular mycorrhizal and dark septate endophyte associations of medicinal plants. Acta Soc Bot Pol. doi:10.5586/asbp.2011.033 